NEAR FINAL DRAFT OF PAPER PUBLISHED AS: G Shaw, A Bailey and A M Williams (2011), 'Service dominant logic and its implications for tourism management: the co-production of innovation in the hotel industry', Tourism Management 32(2): 207-214

\title{
Aspects of Service Dominant Logic and its Implications for Tourism Management: examples from the hotel industry
}

\section{Gareth Shaw ${ }^{1}$, Adrian Bailey ${ }^{1}$ and Allan Williams ${ }^{2}$}

1 Department of Management, University of Exeter

2 Surrey Tourism Research Centre, University of Surrey

\section{Acknowledgements}

The authors would like to acknowledge the funding provided by ESRC and the Advanced Institute of Management for this research. 


\section{Abstract}

This paper introduces the concept of service-dominant logic as a research paradigm in marketing management. It does so in the context of tourism management's need to engage with wider debates within the mainstream management literature.

Moreover it demonstrates the importance of service-dominant logic in uncovering the role played by co-production and co-creation in the tourism industry. These ideas are developed in detail through a case study of the UK hotel industry that draws on new empirical research undertaken by the authors.

\section{Keywords}

Service-dominant logic, co-production, co-creation, hotel innovation

Service Dominant Logic and Its Implications For Tourism Management: the coproduction of innovation in the hotel industry

$\underline{\text { Introduction }}$ 
The engagement of tourism management with research in what can be called 'mainstream management literature' remains highly uneven (Li and Petrick 2008). In some areas this dislocation is increasingly being recognised with attempts by tourism researchers to incorporate new conceptual frameworks as evidenced by the recent discussions of knowledge management and knowledge transfer mechanisms within tourism (Cooper 2006; Yang and Wan 2004; Hallin and Marnbury 2007; Shaw and Williams 2009). However, there are other key developments, particularly within marketing management that have been largely neglected in tourism management studies. Of particular note is the relative failure of tourism research to incorporate the growing body of work on what Vargo and Lusch (2004) have described as service dominant logic (S-D Logic). Such omissions have also been discussed briefly in the context of S-D Logic by Li and Petrick (2008) who argue 'that more research is needed on the tenets proposed by Vargo and Lusch' (p.241); a challenge taken up by this paper.

The ideas surrounding S-D Logic stands in marked contrast to more traditional approaches based on so-called goods - dominant logic (Lusch and Vargo 2006). The former is particularly relevant to tourism management since it 'is based on an understanding of the interwoven fabric of individuals and organisations' (Lusch et.al. 2007:5). In this context it gives critical importance to the value-creating processes which involve the customer as a co-creator of value (Payne et.al. 2008:83; Lusch and Vargo 2006). The approach highlights the customer - supplier relationship through interaction and dialog. The tourism sector is increasingly based around the customer experience and as such suppliers and consumers interact more closely together at all stages of their relationship. The shift to tourism products based much more on consumer experiences has been linked to Pine and Gilmore's (1998) notions of the 'experience economy' or what other commentators have in part viewed more generally as shifts in consumption from Fordism to post-Fordism (Shaw and Williams 2004).

The general aim of this paper is to introduce the concepts of S-D Logic into a tourism management setting. This aim is achieved in a number of ways. First as we argue in this paper the application of the concepts of service dominant logic provides a framework with which to examine supplier - customer processes involved in cocreating the visitor experience. In this context we present an overview of the ideas of service dominant logic and the current state of research within the mainstream literature of marketing management, before going on to consider its implications for 
research in tourism management. Secondly we illustrate its applications in more detail using case material from our current research on innovations in the hotel industry.

\section{The development of service dominant logic in marketing management}

Amongst other premises, service dominant logic (S-D Logic) views 'the customer as an operant resource...' capable of acting on other resources, a collaborative partner who co-creates value with the firm' (Lusch et.al 2007:6). In this context customers become active participants in the work of an organisation. More specifically, Auh et.al. (2007: 361) define such co-production 'as a constructive customer participation in the service creation and delivery process' requiring meaningful and co-operative contributions.

More broadly we can view S-D Logic as three key inter-related aspects. First, it can be viewed as a major paradigm shift in marketing, responding to the call of Sheth and Parvatiyar (2000) for an alternative view of marketing. In this context, Lusch and Vargo (2006) and Lusch et.al (2007) have outlined a new dominant logic for marketing, 'in which intangibility, exchange processes and relationships are central' (Lusch and Vargo 2006: 10). S-D Logic therefore argues that marketing is a continuous social and economic process mainly focussing on operant resources. Second, they have identified nine foundational premises that underpin competition through service. As Lusch et al (2007: 8) explain, such a perspective is related to the key drivers of firm competitiveness, applied knowledge and collaboration. This leads to a third and related theme in which the firm needs to consider 'environments, customers and partners as operant resources' (Lusch et.al 2007: 8; Li and Petrick 2008).

Whilst acknowledging the inter-related nature of these themes, our particular concerns in this paper are the ideas within S-D Logic that encompass the processes of co-production or co-creation, particularly in terms of both incremental and discontinuous innovations. Michel et al (2008) attempt to demonstrate that S-D Logic perspectives enhance understanding of discontinuous innovations, which are identified as those that both change significantly how customers co-create value and also impact on market share. To understand the basis of these ideas within S-D Logic we need to give more attention to the contrasts between operand and operant resources. In terms of the former, the customer is viewed entirely as a resource 
upon which marketers examine, analyse and then promote products to them. This is the more familiar and traditional approach to marketing which segments the customer base prior to developing a marketing strategy. In contrast, from the perspective of SD Logic customers are seen as operant - a resource that produces effects, or coproducers of a service. Auh et.al. (2007: 359) stress that co-production 'has become a central tenet of a proposed service centred logic for marketing': whilst Bendapudi and Leone (2003: 14) argue that it may well be 'the next frontier of competitive effectiveness'. In terms of the firm the process of co-production can be significant in helping to lower costs since the customer participates in parts of the production process (Auh et.al. 2007). For example, within the tourism industry increasing numbers of consumers use the internet to search, arrange and book their holidays. For many consumers the search process and the arranging of holidays around information based on the internet is part of their experience (Litvin et al. 2008; Pan and Fesenmaier 2006). Similarly, the rapid growth of low cost airlines is based around a business model that is highly dependent on the co-production of booking flights via the internet (Mintel 2005;Gross and Schroder 2007). In turn the customer benefits by price reductions and as the early discussions by Lovelock and Young (1979) pointed out such gains are particularly important in the consumer service sector dependent as it is on labour-intensive processes. It also requires 'a shift to a buyer-centric business model' (Auh et. al 2007: 360) which is focussed around coproduction and consumer preferences. Effectively new products and services are developed with close customer involvement. This type of so-called open innovation culture is being used across a range of business organisations (Huston and Sakkab 2006); Chesborough 2006; Vrande et al 2009). For example, Proctor and Gamble have enshrined within their mission statement that 'the consumer is boss'. This embraces the idea of co-production, because consumers 'who buy and use Proctor and Gamble products are valued not just for their money but as a rich source of information and direction' (Lafley and Charan 2008a: 44). This same organisation has also developed new ways of building social connections with consumers via digital media and, as discussed later in the paper, such processes are already significant within the hotel industry.

The co-production process is just one critical dimension of S-D Logic and open innovation culture. Other key elements include engaging more effectively with employees and understanding them as operant resources. This, as Lafley and Charan (2008a : 47) argue, embraces a business culture based on 'curiosity, collaboration and connectedness'. Re-organising a firm such as Proctor and Gamble 
into one based around the ideas of S-D Logic also requires a new leadership culture based around innovative knowledge and skills, which in turn changes the role of the team leader or manager - employee interactions (Lafley and Charan 2008b; Yang 2008).

These ideas about collaborative competence and competitive advantage cover the first, two key propositions of S-D Logic (table 1). The ability to innovate is of critical importance and relates to a firm's collaborative competence. This in turn aids both absorptive competence and adaptive competence (Lusch et.al 2007: Michel et.al 2008). The former relates to a firm's ability to understand and absorb new forms of tacit and explicit knowledge from external sources. The notion of adaptive competence relates to these ideas since it describes the ability of the firm to adapt or adjust to changing circumstance. Both are of critical importance to firms within the tourism sector given the dynamic nature of changes in demand. Such notions also relate to a firm's competency in dealing with information technology at a number of levels, i.e. within the firm, as well as including the customer. This in turn relates to ideas of connectivity which makes 'the market system more timely and quick' to respond to changes (Lush et.al 2007: 10). The increased importance of the digital economy based around the web and high speed connections has led to 'an unprecedented number of touch-points between the firm and end-consumer' (Etgar 2008: 99; Blazevic and Lievens 2008). These ideas relate to the third proposition of S-D Logic (table1) which also raises the importance of information technology in providing increased competitive opportunities through co-creation of value and coproduction (see also proposition four in table 1). S-D Logic views co-creation of value as determined by the user during the actual process of consumption. This closely relates to the consumption experience as discussed by Pine and Gilmore (1999), but co-production focuses on the process of creating the product/service. This process, as Etgar (2008) explains, 'encompasses all cooperation formats between consumers and production partners' (p.98). Evidence also suggests that co-production depends on a variety of factors but of particular importance are the characteristics of individual consumers with, as Pralahad and Ramaswamy (2004) argue, each consumers uniqueness affecting the process.

\section{Table 1 Key Propositions of Service-Dominant Logic}




\begin{tabular}{|c|c|}
\hline & $\begin{array}{l}\text { resources to cater for the consumers compared with how other firms } \\
\text { use such a resource. }\end{array}$ \\
\hline 2. & $\begin{array}{l}\text { Collaborative competence is a main determinant of a firm's knowledge } \\
\text { acquisition for competitive advantage. }\end{array}$ \\
\hline 3. & $\begin{array}{l}\text { The increasing importance of IT provides opportunities for firms to gain } \\
\text { competitive advantage through collaborative innovation. }\end{array}$ \\
\hline 4 & $\begin{array}{l}\text { Firms can obtain competitive advantage through engaging customers } \\
\text { and value network partners in co-creation and co-production. }\end{array}$ \\
\hline 5. & $\begin{array}{l}\text { Competitive advantage through innovation can be gained by an } \\
\text { understanding of how the customer integrates and experiences } \\
\text { service-related resources. }\end{array}$ \\
\hline 6. & $\begin{array}{l}\text { Provision of service co-production opportunities and resources } \\
\text { consistent with customer levels of involvement enhances experiences } \\
\text { leading to improved competitive advantage. }\end{array}$ \\
\hline 7. & $\begin{array}{l}\text { Firms can compete effectively by the adaption of collaboratively } \\
\text { developed and risk-based pricing value propositions. }\end{array}$ \\
\hline $8 a$. & $\begin{array}{l}\text { The firm that is the value network member that is the prime integrator is } \\
\text { in a stronger competitive position. }\end{array}$ \\
\hline 8b. & $\begin{array}{l}\text { The retailer (e.g. hotel) is generally in the best position to become the } \\
\text { prime integrator. }\end{array}$ \\
\hline 9. & $\begin{array}{l}\text { Firms that use their employees as operant resources are able to } \\
\text { develop more innovative knowledge and skills increasing their } \\
\text { competitive advantage. }\end{array}$ \\
\hline
\end{tabular}

Source: modified from Lusch et al. 1992

The importance of the characteristics of the customer in the co-production process is highlighted in proposition 5 as shown in table 1. Lusch et.al (1992) identify six main factors that determine the extent of the customer's role in co-production (table 2). Smith and Wheeler (2002) and Etgar (2008) also stress that the customer skill sets are a source of 'touch points' and can aid in the management of their experiences (see also Schmitt 2003). Such touch points are numerous in tourism as highlighted by Shaw and Williams (2009) and also play a key role within the co-creation processes identified in S-D Logic. The factors highlighted in table 2 suggest that engagement in co-production is highly selective which has implications for the range 
and management of co-production processes involving consumers, at least in terms of the initial phases of product and service innovations.

Table 2 Key Factors Conditioning Customer Contributions to the Coproduction Process

Factors $\quad$ Impact on Co-production

Expertise

Control

Consumer Capital

Experiential Benefits

Economic Benefits

Time
Consumers likelihood of participation depends on expertise (co-ordination of skills, efficiency and evolving experience). Also importance of computer based skills.

More involvement when individual wants to exercise some control.

Increased level of involvement if consumer has requisite cultural or physical capital.

Gaining of experiential benefits involving new activities.

Perceived economic gains play a key role in co-production processes.

Consumers with more discretionary time more likely to engage in co-production.

Source: modified from Lusch et.al (2007) and Etgar (2008)

The descriptive co-production model outlined by Etgar (2008) embraces five key stages, namely: (1) the development of antecedent conditions related to macroenvironmental factors and changes in consumer culture. This includes the ways in 
which consumers interact with service producers; (2) the development of motivations that encourage consumers to engage in co-production. These include economic and socio-cultural drives as well as risk reduction, whilst Etgar $(2006,2008)$ argues that cost reduction can often be a key motivator for consumer co-production. Certainly the use of internet booking for holidays and low cost airlines saves time and money. This was a major driving force for the early take-up of e-booking although evidence suggests that internet searches for holidays is now part of a pleasure activity itself (Oorni 2004); (3) the calculation of co-production cost benefits; (4) activation during which consumers become fully engaged in the co-production activities; (5) the generation of outputs and evaluation of the co-production process Etgar's (2008) work is significant in highlighting the components and stages of the co-production process as well as in linking with the fundamentals of S-D Logic. However, as Etgar explains it is very much an 'explicit consumer strategy' (p.105), whilst in this paper we are particularly interested in the co-production process from the managerial perspective of the organisation. These specific ideas are explored within the context of tourism management and more particularly via a case study of the hotel industry. In this context we attempt to draw out some of the managerial implication of coproduction with consumers.

The experience economy: creating consumer experiences and the importance of coproduction

Pine and Gilmore (1998; 1999) have argued that post-modern forms of consumption relate to a changed economy based on experiences rather than just services and goods. In their recognition of the so-called emerging experience economy, they encapsulated previous thinking about the growing importance of consumer experiences as discussed by Holbrook and Hirschman (1982). Pine and Gilmore (1998) went further and highlighted the significance to both consumers and producers of creating memorable experiences associated with the consumption of services and products. Memorable experiences are particularly associated with excellent design, marketing and service delivery and have two dimensions; firstly, consumer participation which ranges from passive to active and, secondly, the connection which links the customer to the experience event (Pine and Gilmore 1998). The creation of such experiences is of obvious significance in tourism and further stresses the importance of co-production. This is due to the demand for customised experiences as the interactions of consumers with providers change (Etgar 2008). Single exchange transactions are changing into relationships wherein 
value is created through the interaction process itself (Gronroos 1990; Etgar 2008). This idea in turn relates to the notions of open innovation and S-D Logic. As Lusch et al (2007) stress, the shift to S-D Logic is also the difference between value delivery (under Goods Dominant Logic) and value creation. The latter is associated with coproduction, with its emphasis on customers as an operant resource, and has become increasingly important in many parts of tourism. It is also worth stressing that Lusch and Vargo (2006) argue that historically value has always been co-produced, but only recently have co-production processes been identified and consciously integrated within service management. As they point out, this shift to SD Logic is related to marketing management practices rather than the ontology of value creation.

Etgar (2008) highlights how the characteristics of products (p.100) influence the unevenness of co-production processes across different business sectors. The key characteristics are the existence of major differences in the attributes of products which may be both physical and perceived. In terms of consumer perception, the perceived importance that consumers attribute to such differences is of particular significance. Within tourism such differences are often clear to consumers and, in these circumstances, consumers are more willing to get involved in the co-production process. Conversely, in terms of value creation, it is critical that producers also fully recognise the importance of co-production, especially in terms of innovation.

Pine and Gilmore (1998) originally saw the value creation process from the producers' perspectives as being associated with five main principles of designing the customer experience, all of which are pertinent to tourism. Of course what Pine and Gilmore did not discuss was the critical importance of implementing such ideas through the innovation process, which could be significantly strengthened through the co-production processes embedded with S-D Logic. Therefore, whilst some researchers within tourism took up the challenge of the 'experience economy' this was somewhat partial (Shaw and Williams 2004; Weiermair and Mathies 2004). Since Pine and Gilmore's initial work, consumer experiences have been increasingly transformed by the growing importance of the world wide web, and in particular, the development of social network sites made possible by Web 2.0 technologies (Buhalis 2003; Buhalis and Laws 2008). As Buhalis and Laws (2008: 612) explain, the developments of on-line communities 'makes it easier for people to obtain information, maintain connections, develop relationships and eventually make travel related decisions'. Moreover social network sites, blogs and twitters are means by 
which consumers can provide views on travel experiences (Wang and Fesenmaier 2004). The most recent growth has been associated with Twitter the micro-blogging website that had more than 6m users posting updates each month in 2009 (Rushe 2009). As Google (2008a: 1) explain, the 'on-line market has rapidly become the number one resource for the travel consumer' in the UK. Their research suggests that in the first quarter of 2007 there were $20 \mathrm{~m}$ on-line searchers in the UK representing almost $41 \%$ of the population. Other research from Google (2008b) claims that, in the UK, the average time spent on-line per week is 12 hours and that a typical search for beach based holidays involves, on average, 12 different searches across 22 travel sites.

Of equal significance is the enhanced potential offered by the web for co-production to take place in the virtual environments represented by social network sites. Such sites are increasingly important sources of marketing information about consumer experiences. These developments have led some commentators to suggest we are now in a 'conversation economy' (Hotelmarketing.com 2007). The rapid growth of these social, e-media sites have in part shifted power to consumer communities - at least in terms of market information (Rosen 2000). Increasing numbers of consumers now have their experiences shaped by on-line searches together with the use of multi-media (Thinkbox 2008) and social network sites such as TripAdvisor (Buhalis and Law 2008). Research into the leading destinations and accommodation websites in terms of page rank for the UK, in 2008, reveals that TripAdvisor (5.44\%) had the largest market share, followed by Travelodge (4.98\%), TripAdvisor UK (3.95\%), Booking.com (3.11\%) and LateRooms (2.62\%) (Hitwise 2008). Moreover, such trends have brought a new and important dimension to co-production in parts of the tourism industry. According to Kirkby (2008) it is increasingly recognised that online socialisation amongst consumers significantly facilitates producer - customer engagement. Many of these consumers are looking both for conversations with each other, together with expectations of some interaction with and influence on producers. Within the context of tourism managers, Litvin et al (2008) highlight the need to develop new ways to understand the influence of such e-conversations to tourism organisations. We would argue that S-D Logic provides an useful framework for such an understanding.

Despite its obvious value, engagement with S-D Logic in tourism has been limited and partial, including notions of customer participation in service encounters (Liu, et al. 2007) and the more substantive but general review by Li and Petrick (2008). This 
stands in marked contrast to work on other sectors such as financial services (Auh et al. 2007), services more generally (Michel et al. 2008) and business services and coproduction in the public sector (Kuusisto and Viljamaa 2004). Clearly there is considerable scope to explore the ideas of co-production within a tourism context, and this is illustrated here by empirical material drawn from recent research on innovation and co-production within the hotel industry.

Co-production processes from a Service-Dominant Logic perspective: examples from the hotel industry

S-D Logic emphasises that the role of consumers in the co-production process is critical to understanding competitiveness. This is particularly so, as argued earlier, in terms of absorptive and adaptive competences (Stefan et al 2008). The focus on the customer as an operant resource also opens up different roles for customers in the co-production process. According to Sheth and Mittal (2004), there are three key roles with customers as users, buyers and payers. These, of course, apply to customers in different contexts. In terms of S-D Logic, these in turn relate to valuein-use (user's role), value-in-exchange (buyer's role) and the payer's role embraces both value-in-exchange along with value in use (Stefan et al 2008). Discontinuous innovations can and do change customers' roles, as Stefan et al (2008) illustrate with a range of short examples. Within the hotel industry, these changing roles are associated with innovations particularly, though not exclusively, surrounding ecommerce.

In this part of the paper we want to draw on a number of case study to illustrate the changing nature of co-production processes and the importance of customer as operant. These processes require certain types of expertise from the consumers as highlighted in table 2, but as we shall show there are also implications from a management perspective. Before doing so it is necessary to set the work in context and explain the selection of case studies. Our examples are drawn from a wider survey which forms part of a research project on internationalisation and innovation in the hotel industry. Table 3 shows the selected sub-sample of case studies used in this paper which range from national independent hotels (medium-sized enterprises) through to international hotel companies. As table 3, illustrates a variety of key informants were interviewed and, in this respect, variations in emphasis can be expected relating to the interviewee's position within the organisation. However, all the respondents were asked the same question in interviews which lasted around 2 
hours on average. The interviews focussed on aspects of innovation, knowledge and co-production. In terms of the latter, this included co-production along the entire value chain and not only with customers. Given the aims of this paper, we focus mainly on the latter.

Other attempts to report consumer co-production, for example in financial services (Auh et al. 2007), have taken a quantitative approach using information from customers. Our research methodology centres on the producer and is qualitative in nature given the need for in-depth empirical information in order to understand producer's activities around co-production. Our hotel survey reports on two key themes; first the extent of co-production with customers and, secondly, the detailed processes involved in this.

In terms of the former all the cases in our sample exhibited some degree of customer interface as one would expect in an industry dominated by the service experience. However, only a few of the interviews revealed any collaboration of the type identified within S-D Logic, i.e. where the consumer was acting as an active operant resource in the co-production process. At a broad level two distinct groups of hotels can be identified in terms of the extent of customer co-production. The first group, which represented the majority of cases in our sample, were not actively embracing coproduction as an overt part of the operational or marketing strategy, although some were beginning to think about how to engage more with consumers. This group included hotels of all types from budget to Five Star, covering cases B, D, F, G and H in table 3. In contrast, the second group, represented by hotels $A, C$ and $E$, had one key characteristic in common, being that their keenness to innovate, in addition to being actively involved in consumer co-production. As with the first group, these hotels were drawn from diverse parts of the industry. This is not to imply that the hotels in group one were not innovating, but rather that the interviews suggested that innovation did not seem to be a key driver in their business plan.

\section{Table 3 Case Study of Hotels from the Survey Sub-Sample}




\section{Turnover}

\section{Hotel Code/Type}

A National Hotel Group

B National Hotel Group

C National Hotel Group

D Major Hotel Chain part of International Group

E Medium Sized Enterprise

F $\quad$ Medium Sized

G Global Hotel Chain

H Global Hotel Co-operation

\section{Characteristics}

Upscale

Upscale

5-6 million

4-5 million

Micro Boutique

Mid-Upscale

+700 million

Not Specified

Upscale

Micro Eco Boutique

New Start Up 2009

Managing Director

Budget

+280 million

IT Director

Midscale

Franchisor

Group IT Manager

Revenue Manager

Marketing Manager +

Finance Manager

Accounts Manager

Owner / Managing

Director

Source: authors' interviews 
In terms of the detailed processes of co-production with customers, it is useful to contrast the approaches taken by the two groups of case study hotels. Within the first group the attitude to co-production was in many instances somewhat tentative. For example, in the case of Hotel B the response to our questions about coproduction was to talk in general terms about guest comment cards stating 'She [the 'champion' appointed at each hotel] sits down once a month and goes through them one by one, and anything negative she reacts to'. The hotel group had recently started to look at comments on TripAdvisor 'making sure that if anything negative is posted we respond to it'. As the interviewee (the revenue manager) went on to explain 'Other than general ad-hoc comments I really don't think I've done anything major with what we have'. One exception being; 'Refurbishments, we tend to listen to what our guests tell us particularly with in-room technology, you know there's this big question of whether we will still charge for Wi-Fi or not'. The one pro-active approach they had introduced was that guests who book via the web site get an email from the Managing Director asking for any comments. However, the respondent stated, 'he regrets doing this now with the amount of work it's making'. This contrasts with the increasing importance noted in the research literature on the harvesting of customer opinions across the hotel industry (Pekar and Ou 2007). It is worth pointing out that the hotel's response to comments on TripAdvisor was itself unusual within this group.

Examples from the second group of hotels highlight their drive for innovation as a competitive strategy together with increasing awareness of and capability for coproduction. In hotel A, the importance of innovation was emphasized by the interviewee at the outset. This was enabled by the close management structure, for example between the group's managing directors and the head of IT (the interviewee) who stated; 'I can go and chat to him and talk to him about new technology and he's been very passionate all a long the way of investing in technology'. One of the key innovations discussed concerned the development of inroom entertainment, which across the hotel industry is seen as an increasingly important competitive product (Martinez-Ros and Orfila-Sintes 2009).

Hotel A illustrates the complexity of co-production both with the IT supplier (Apple) and the consumer. In the case of the former the hotel co-produced with Apple an inroom entertainment system based around an iMac solution. This required a high degree of product testing and experimentation by the hotel. According to the interviewee the starting point was a great deal of: 'trial and error, we tried out a few 
bedrooms and got guests to fill in questionnaires and see the feed back about what they liked'. Closer collaboration was then needed with customers to help perfect the product. This took the form of: 'rather than trialling it on a customer who could generate a complaint, we would maybe give him (sic) a bit of a prep beforehand and say, look we're trying this out and here's the bottom line'. In many instances it was regular customers that were used primarily because they were perceived as having the user skills or, as Lusch et al (2007) and Etgar (2008) argue, the necessary 'expertise and consumer capital (table 2). This stage involved a trial with 60 customers giving detailed feedback on their experiences. As the interviewee explained, the customers were interviewed by the hotel staff 'on one to one basis the night after using it [the iMac in-room system] and went through it and you know they kind of helped us build a business case'.

The final co-production stage involved a two month period during which the iMac product was placed in 10 rooms in one of the company's London hotels. At this point they estimated that the product 'was probably $70 \%$ of the way there'. In this context the system was being tested on new, less experienced customers. According to the interviewee these final stage tests were 'used to gauge other guests concerning the effectiveness' of the iMac technology in the bedrooms. In the case of Hotel A the coproduction process surrounding the innovation was developed across three key stages, each of which had differing elements of co-production using the consumer as operant in slightly varying ways. Moreover, information from these stages was fed back into the co-production with Apple enabling the product to be further refined.

Our second case of co-production involves a design-led innovation and related business model being applied by hotel $\mathrm{C}$ (located in Birmingham). In this case the innovation is based around bedrooms that are prefabricated pods. This, as one of the interviewees (marketing manager) explained, was 'very much a business decision and a niche in the market and it bridged that gap between budget and luxury'. The early stage of co-production, in this case, was to test the ideas of the pod-designed rooms on an 'initial reaction from customers, based literally on a description and then visuals'.

Given the nature of the innovation it soon became apparent that consumer reactions need to be more fully gauged by constructing a prototype. This was because 'it's a very difficult concept to visualise because there was nothing else like it'. Hotel $\mathrm{C}$ also had an extensive customer monitoring system based on face-to-face discussions 
with customers, in-room questionnaires and social network sites, particularly TripAdvisor. However, unlike Hotel $\mathrm{B}$, the marketing manager at Hotel $\mathrm{C}$ considered TripAdvisor as a domain for consumers and had never sought to engage consumers directly through the site. For Hotel E, however, the provenance of customer feedback generated by social network sites was difficult to establish:

'TripAdvisor is something that we look at, the down side of TripAdvisor is the fact that it is an open community not a closed community and actually what a few hotel groups have been doing is putting bad reviews on competitor sites, really noticeably actually, a couple of groups are quite bad at that.'

Hotel $\mathrm{E}$, is a family owned luxury group, which operates in a market where higher levels of customer service and engagement would be expected compared to the budget sector. Imaginatively titled feedback cards provide Hotel E with feedback about their room and conference services. The feedback is scrutinised by management committees, which seek to improve and innovate the service provided. More innovative is the use of focus groups, drawn from key clients:

'They love doing it and also they get flown over to Spain and put in a nice hotel for two days and there's a wine tasting in the evenings that's fun, so it's only four hours of work for them but we work them hard.'

These relaxed meetings are essential in facilitating mutual learning on behalf of the client and the service provider. For example, a leading law firm expressed dissatisfaction with the provision of 24 hour rolling coffee breaks, requesting that the Hotel 'make it more funky'. Through engaging the client as an operant resource, Hotel E was able to establish that 'funky' meant: (i) delivering 'the Starbucks' experience' in the hotel context, (ii) flexibility in the timing and delivery of the service, and (iii) an element of fun. The improvement to the service was subsequently achieved through the creation of a 'sweet-shop', which was personalised for different clients, and via the introduction of technology that could deliver various styles of coffee on demand. The personalisation of hotel services at Hotel $\mathrm{E}$ can be relatively large scale, such as the overhaul of conference hospitality, but is more often conducted at a micro-scale with reference to individual guest histories. The managing director acknowledged that there are limits to the involvement of the client 
in the innovation process, because it would be difficult to maintain elements of surprise that are deemed essential to maintaining customer satisfaction; 'we call them critical non-essentials, so it's those silly little touches that you go away and say "oh wow you'll never guess what"'.

Hotel $E$ has recently introduced an innovative multi-sensory dining experience, where customers are seated 'back stage' to view the processes and skill it takes to prepare their menu, and to interact with the staff. The managing director argued that the consumers' role as co-producers did not extend to the innovation of the physical product, but was significant in shaping the offering. For example:

someone made a comment about, "I don't know who does what in the kitchen", so we changed the aprons so the ... banqueting team wear blue, ... [another] team wear green and the pastry team wear red aprons, and actually that's very low cost tiny tweak but that change means people walking in and it becomes a talking point

Finally Hotel G, a budget hotel chain, engages the specific capabilities of customers to improve the technical interfaces between the hotel and the customer. During the launch of a new website booking engine, Hotel $\mathrm{G}$ utilised the competencies of two communities. First, their call centre reservation team trialled the website and provided feedback to the director of technology. Second, the Hotel made use of a technical forum, comprising 2,000 people, drawn from a membership list of 1.6 million. The director of technology explained:

we gave those 2,000 technical forum members a link to the beta version of the site, which was a live fully functional version of our website, different $U R L$, and then we had that relationship with a company called Survey Monkey, so completely independent to us, asked them to help and give us word of mouth feedback, tell us instinctively how you felt and we had everything from, I'm using RU6 ${ }^{1}$, you're using Google maps and a lot of Java and its really slow, all the way through to fantastic and then a whole spectrum of comments in between, and we used that to influence the site before we launched the website.... You know, there's a group of early adopters, you know

\footnotetext{
${ }^{1}$ Rollup v.6 (RU6), a term used to denote the upgrading of software, often associated with Microsoft Exchange Servers and operating systems.
} 
when you start to profile people, there is always a group who describe themselves as early adopters and they like innovation and gadgetry and then they got themselves into that network.

In other respects, however, Hotel $\mathrm{G}$ was self-limiting in its use of consumers as operant resources. The business model had two key performance indicators of lowering costs through efficiency gains and service improvement. In both respects, these were more dependent upon innovation within the supply chain than upon engaging guests in co-production interactions.

These case studies provide evidence of the contributions made by customers to the co-production of innovation, a key feature of S-D Logic. In such situations, as Stefan et. al (2008) argue, customers are required to play new roles conditioned by certain key factors (table 2). This interface with customers is important in a number of ways and as Sundbo (1997) points out innovation often focuses on a specific customer need. Within the hotel industry there is an emerging trend of customers being viewed as an operant resource in the co-production process surrounding innovation, although this is not as yet the dominant paradigm in our sample (e.g hotels B, D, F, G and $\mathrm{H}$ do not engage in such a process).

There are important management implications of such co-production processes, not least in how businesses engage with the customer, although our case studies also emphasise the need to guard against over generalisation. The case studies highlight the importance given by hotel management to customer expertise although this is not to deny that experiential, economic and time considerations may also be critical to individual consumers. Moreover, one case study (hotel E) emphasises that some firms understood the importance of a virtuous circle of mutual benefits. Customers were more likely to be operant co-producers where there were experiential and economic benefits, such as a trip to Spain in return for focus group participation. This highlights the customisation of innovation as discussed by Stefan et al. (2008) and Berry et al.(2006).

Hotels also sought customers who could articulate views on potential innovations, and this required knowledge of the product or process, with one firm (hotel A) favouring regular customers as operants. The same hotel had a hierarchical 'map' of their customers, engaging with selected regular customers in the formative coproduction stage of innovation and other customers in the confirmative final stages of 
testing prior to rolling out the innovation across the hotel network. This required a considerable degree of management expertise in the different stages of coproduction.

Another important area of importance for hotels is that customers involved in coproduction should have expertise in IT. At one level this may only require the ability to deal with on-line surveys or participate in social network sites. However, coproduction can also demand relatively high levels of competence, as evidenced by the firm (hotel $\mathrm{G}$ ) which worked with a specific group of customers to test out an initial innovation. More generally, Bitner et al. (2000) explain that IT can be a significant tool through which customers co-create value in such encounters.

The case studies also highlight the need to balance the focus given by Lusch et al. (2007), Etgar (2008) and others to the conditions fostering customer involvement in co-production, along with an understanding of how this interacts with the firm's ability to understand and negotiate such processes. The latter has management implications that, in part, relate to those customer conditions identified in table 2. For example, to harness customer expertise the firm requires a management environment which embraces knowledge sharing amongst its workforce. Etgar (2008) goes further arguing that those employees who act as 'boundary spanners' (Shaw and Williams 2009) are critical to the process of co-production. These ideas also relate to shared goals and understanding amongst staff. The case studies show such experiential benefits (table 2), to varying degrees, as was visible in the case of hotel A where the group IT manager played a key management role in the coproduction of the innovation.

\section{$\underline{\text { Conclusion }}$}

Recent research in marketing management has increasingly been drawn to the concepts and ideas encompassed by S-D Logic, with its emphasis on co-production. In this paper we have introduced and developed these ideas to demonstrate their particular relevance for tourism management. This is not only to help stimulate tourism research to engage more strongly with this and other wider debates within contemporary management studies, but also because such ideas provide a fresh perspective on product development in tourism. Consumer experiences are at the very heart of the tourism industry and S-D Logic provides a conceptual framework for 
understanding how the consumer is becoming central to the development and marketing of tourism products through a process of co-production with the producer.

This paper has discussed key aspects of S-D Logic particularly in terms of the notions of the experience economy and the development of new products/services. S-D Logic encompasses coproduction through the entire value chain but, in this paper, we have focussed on the co-creation of value between the producer and the consumer, arguably one of the most dynamic areas of innovation in the industry. More specifically, we have drawn on new, empirical research on innovations in the hotel industry that have, in part, focussed on co-creation with the customer. The small group of case studies introduced here suggest that those hotels which aim at development through product/service innovation are indeed strongly reliant on implementing co-creation strategies with customers. One case study in particular indicates that such processes are highly complex and suggests that co-creation is already relatively well advanced in some elements of the tourism industry, even if research lags behind in this field.

Our paper provides a first detailed discussion of the concepts of S-D Logic in the context of tourism management and we would argue that it suggests that such ideas provide a number of exciting opportunities for further research. As an immediate priority, we would suggest there are four important issues that require research attention. First, how do scale, ownership, corporate structures and business strategies influence the approaches of firms to co-production and the S-D logic. Secondly, what are the key aspects not only of adoptive capacity but also absorptive capacity in respect to the ability of firms to both recognize and maximise the competitive advantages that can be derived from co-production? Thirdly, how does IT not only change the scope of the interactions which are at the heart of the producerconsumer relationships, but also change the power relationships within these; in particular, how does the growth of on-line communities empower and inform individual consumers as co-creators of new tourism products. Fourthly, in what ways are different forms of producer-consumer co-production selective in terms of the guests who are engaged in this process, and are there significant differences in their effectiveness. Beyond this, there is also a need for research on other aspects of S-D Logic, both further along the value chain, and in terms of the engagement of employees in knowledge sharing via different means (Salis and Williams 2010). 
Bibliography

Auh, S., Bell, S.J., McLeod, C.S. and Shih, E (2007) 'Co-production and customer loyalty in financial services', Journal of Retailing 83 (3): 359-370

Bendapudi, N. and Leone, R.P. (2003) 'Psychological Implications of Customer Participation in Co-Production; Journal of Marketing 67 (1): 14-28

Berry, L.L., Shankar, V., Parish, J., Cadwallader, S. and Dotzel, T. (2006 'Creating new markets through service innovation', MIT Sloan Management Review 47 (2): 5663

Bitner, M.J., Brown, S. W. and Meuter, M.L. (2000) 'Technology infusion in service encounters', Journal of the Academy of Marketing Science 28 (1): 138-149

Blazevic, V. and Lievens, A. (2008) 'Managing Innovation through customer coproduction knowledge in electronic services: an exploratory study', Journal of the Academy of Marketing Science 36 (?): 138-151

Buhalis, D. (2003) e Tourism: information technology for strategic tourism management London: Pearson

Buhalis, D. and E. Laws (2008), e Tourism case studies: management and marketing issues London: Butterworth-Heineman

Cooper, C. (2006) 'Knowledge Management and Tourism' Annals of Tourism Research 33 (1): 47-64

Etgar, M. (2006) 'Co-production of Services: a managerial extension' in Lusch, R. F., Vargo, S.L. (eds) The Service Dominant Logic of Marketing, Armour: M.E. Sharpe

Etgar, M. (2008) 'A descriptive model of the consumer co-production process', Journal of the Academy of Marketing Science 36: 97-108

Google (2008a) 'How-to Guide for Online Conversions: 5 essential tools for agencies', Google (www.google.c.uk/insights/search accessed April 2009).

Google (2008b) 'A New Model for Building Brands'

(http://www.youtube.com/watch?gl=GB\&hl=en-GB\&v=NRthYjl8rZs (accessed Jan 2009)

Gross, S. and Schroder, A (eds) (2007) Handbook of Low Cost Airlines, Gottingen: Hubert and Co.

Gronroos, C. (1990) 'The relationship approach to marketing in service contexts', Journal of Business Research 20 (1): 3-11

Hallin, C. A. and Marnburg, E. (2007) 'Knowledge management in the hospitality industry: a review of empirical research', Tourism management 29: 366-381

Hitwise (2008) 'Hitwise Industry Report for Travel - Destinations and Accommodation' London: Hitwise 
Hotelmarketing.com (2007) 'The Conversation Economy' (http://www.hotelmarketing.com/index.php/content/article/070412 the conversation economy/ Accessed April 2009)

Holbrook, M.B and Hirschman, E.C. (1982) 'The Experiential Aspects of consumption: Consumer Fantasies, Feelings and Fun', Journal of consumer Research 9 (2): 132-140

Hotelmarketing.com (2007)

Huston, L. and Sakkab, N (2006) 'Connect and Develop: inside Procter and Gamble's New Model for Innovation', Harvard Business Review 84 (3): 58-69

Kirkby, J. (2008), 'Is there value in socialising with customers?' http://www.mycustomer.com (accessed 18/04/07)

Kuusisto, J. and Viljamaa, A. (2004), 'Knowledge - Intensive Business Services and Co-production of Knowledge - the role of the Public Sector?', Frontiers of E-Business Research : 282-298

Lafley, A.G. and Charan, R. 2008a 'P\&G's Innovation Culture', Strategy and Business 52 (Autumn): 41-49

Lafley, A.G. and Charan, R (2008b) The Game-Changer. How you Drive Revenue and Profit Growth with Innovation, Crown Business

$\mathrm{Li}, \mathrm{X}$ and Petrick, J.F. (2008) 'Tourism Marketing in an Era of Paradigm Shift', Journal of Travel Research 46 (Feb): 235-244

Litvin, S. W., Goldsmithy, R.E and Pan, B (2008) 'Electronic word-of-mouth in hospitality and tourism management', Tourism Management 29 (?): 458-468

Liu, W-b, Liv, B and Chen, R (2007), 'Customer participation in the service encounter', Chinese Business Review 6 (4): 52-56

Lovelock, C.H. and Young, R.F. (1979), 'Look to Consumers to Increase Productivity', Harvard Business Review 57 (May/June) 168-176

Lusch, R.F., Brown, S.W. and Brunswick, G.J. (1992) 'A General Framework for Explaining Internal vs External Exchange', Journal of the Academy of Marketing Science 20 (Spring): 119-134

Lusch, R.F. and Vargo, S.L. (2006) 'Service-Dominant Logic as a Foundation for Building a General Theory' in R.F. Lusch and S.L. Vargo (eds), The ServiceDominant Logic of Marketing: Dialog, Debate and Directions, New York: Armonk: 406-420

Lusch, R. F., Vargo, S. I. and O'Brien, M. (2007) 'Competing through service: Insights from Service-dominant logic', Journal of Retailing 83 (1): 5-18

Martinez-Roz, and Orfilia-Sintes (2009) 'Innovation activity in the hotel industry', Technovation 29 (?): 632-641 
Michel, S., Brown, S.W. and Gallan, A. S. (2008), 'An expanded and strategic view of discontinuous innovations: deploying a service-dominant logic', Journal of the Academy of Marketing Science 36: 54-66

Mintel (2005) No-Frills/Low Cost Airlines, Leisure Intelligence Report, London: Mintel

Oorni, A (2004) 'Consumer Objectives and the Amount of Search in Electronic Travel and Tourism', Journal of Travel and Tourism Marketing 17 (2-3): 2-14

Pan, B. and Fesenmaier, D.R. (2006) 'Online Information Search, vacation Planning Process', Journal of Travel Research 33(3): 809-832

Payne, A.F., Storbacka, K and Frow, P. (2008), 'Managing the Co-creation of value', Journal of the Academy of Marketing Science 36 (1): 83-96

Pekar, V. and Ou, S. (2007), 'Discovery of subjective evaluations of product features in hotel reviews', Journal of Vacation Marketing 14 (2): 145-155

Pine, J.B. and Gilmore, J.H (1998) 'Welcome to the Experience Economy', Harvard Business Review 76 (4): ?

Pine, J.B. and Gilmore, J.H. (1999), The experience economy: Work is theatre and every business a stage. Baston: Harvard Business School Press.

Prahad, C.K. and Ramaswamy, V. (2004) The future of competition: Co-creating unique value with customers, Boston: Harvard Business School.

Rosen, E. (2000) The Anatomy of Buzz New York: Doubleday

Rushe, D. (2009) 'Twitter the target of Google Search' The Sunday Times: Business Section, 5 April: 3

Salis, S. and Williams, A.M. (2010), 'Knowledge sharing through face-to-face communication and labour productivity: evidence from British workplaces,' British Journal of Industrial Relations

Schmitt, B.H (2003), Customer Experience Management, New Jersey: John Wiley and Sons

Shaw, G. and Williams, A.M. (2004) Tourism and Tourism Spaces, London: Sage

Shaw, G. and Williams, A.M. (2009), 'Knowledge Transfer and Management in tourism: an emerging research agenda', Tourism Management 30 (3): 325-335'

Sheth, and Parvatiyar, (2000). Handbook of relationship Marketing Paris: Lavoisier

Sheth, J.N., and Mittal, B., (2004) Customer Behaviour. A managerial perspective South Western, Thomson

Smith, S. and Wheeler, J. (2002), Managing the Consumer Experience, London: Prentice Hall/Pearson

Stefan, M., Brown, S.W., Gallan, A. S. (2008) 'An expanded and strategic view of discontinuous innovations: deploying a service dominant logic perspective', Journal of the Academy of Marketing Science 36: 54-66 
Sundbo, J. (1997) 'Management Innovation in Services' The Service Industries Journal 17 (3): 432-455

Thinkbox (2008) 'Talking Metrics with Thinkbox' WebProNews http://www.webpronews.com/blogtalk/2008/01/22 (accessed 31/03/09)

Vargo, S. L. and Lusch, R. F. (2004), 'Evolving to a New Dominant Logic for Marketing', Journal of Marketing 68 (1): 1-17

Wang, Y and Fesenmaier, D.R. (2004) 'Towards Understanding Members' General Participation in and active contribution to an online travel community', Tourism Management 25 (?): 709-722

Weiermair, and Mathies, (2004) The tourism and leisure industry: shaping the future London: Routledge

Yang, J-T (2008) 'Individual attitudes and organizational knowledge sharing', Tourism Management 29 (?): 345-353

Yang, J-T and Wan, C-S. (2004), 'Advancing organizational effectiveness and knowledge management implementation', Tourism Management 25: 593-601 